\title{
Performance Evaluation of Self Excited Induction Generator Using Fuzzy Logic with Variable Machine
Parameter
}

\author{
${ }^{1}$ Er Ashish Sharma, ${ }^{2}$ Raja Singh Khela \\ ${ }^{1}$ Research scholar, Punjab Technical University Kapurthala, Punjab,India \\ ${ }^{2}$ Director -Principal Doaba Group of Colleges Kharar Mohai, India \\ 1ashishdpr@rediffmail.com, ${ }^{2}$ rskhela@,rediffmail.com
}

\begin{abstract}
This paper presents a MATLAB based generalized algorithm to predict the dynamic and steady state performance of Self Excited Induction Generators (SEIG) under any fix combination of speed, excitation capacitor and loading and by varying the other machine parameters such as rotor and stator resistance. The another parameters changed are rotor and stator reactance. The Fuzzy rules are also implemented to model the behavior of SEIG with lagging power factor loads under three operating conditions i.e. variable load operation, variable speed operation and variable capacitance operation. The usual techniques like loop impedance and nodal admittance methods are used to evaluate per unit Magnetizing Reactance (Xm) and Generated Frequency(a) of Self Excited Induction Generator (SEIG) under varying terminal conditions. These mathematical calculations involve complex equations, are time consuming With the recent technological advancements, Artificial Neural Networks (ANN) and Fuzzy Logic (FL) techniques are being used in various industrial applications to determine \& control the performance of machines replacing the conventional methods. The algorithms are implemented as MATLAB user friendly Tool boxes resulting inconsiderable simplification over earlier methods .The advantages of using fuzzy logic approach are universal control algorithm, fast converging, accepting of noise and inaccurate signals. At the end of the paper the theoretical and fuzzy logic results are verified with ANN and analytical data .
\end{abstract}

Keywords: Self excited induction generators, fuzzy logic, artificial neural networks

\section{INTRODUCTION}

To rise above the problems faced in generation of power from conventional energy sources, government and nongovernment generating companies have focused their attention towards non-conventional energy sources. These sources include wind energy, bio-gas, solar and hydro potential, etc. In renewable energy applications of low and medium power, the induction motor operated as a generator offers considerable advantages due to its ruggedness, low cost,brush-less squirrel cage rotor, manufacturing simplicity, low maintenance and wide off-the-shelf range. In addition, it does not require synchronizing conditions to be met before connecting it to the existing electric lines supplying power to the network. Squirrel cage induction motor, generates power when driven by prime mover and connected across excitation capacitors. The SEIG system is composed of four main items: the prime mover, the induction machine, the load and the self-excitation capacitor bank. The self excitation capacitors connected at the stator terminals of the induction machine must produce sufficient reactive power to supply the needs of the load and the induction generator.A self excited induction generator is more cheaper than a conventional synchronous generator and has brushless cage rotor construction, absence of DC excitation source and lower maintenance requirement are its attracting features. A suitably sized three-phase capacitor bank connected at the generator terminals is used as variable lagging VAR source to meet the excitation demand of the machine and the load. The operation of machine in this mode is called Self-excited Induction Generator. While operation of the induction motor in the generating mode while connected to the grid is straightforward to analyze using the standard equivalent circuit due to the rigid frequency and voltage of the grid, its analysis and operation as a stand-alone power source is complicated since both the voltage and frequency are now variables and involves solving non linear equations of higher order. Under these conditions proper selection of equipment and the prediction of the system performance are essential for successful implementation of the scheme. To determine the performance analysis of SEIG, various 
researchers used different methods [1-5] to determine the parameters of induction generator. The present work takes advantage of the MATLAB software package to make the numerical computations easier, by combining all the available methods into a user-friendly toolbox for MATLAB as it results in considerable ease of analysis. Results are presented for various combinations of inputs, thus enabling the designer to decide on the best setup. the performance of any machine with given parameters as shown in Appendix-II has been evaluated. The evaluation is done using fuzzy logic and the results obtained are compared with the analytical and ANN, which shows close agreement signifying the uniqueness of fuzzy logic approach.

\section{EQUIVALENT CIRCUIT OF SEIG AND ANALYTICAL TECHNIQUE}

The performance of the SEIG using an analytical model based on a conventional single-phase equivalent circuit with per-unit (p.u.) parameter has been studied in the past. The model used has also been extended for the evaluation of various steady-state performance characteristics of stand-alone generators, like the effect of shaft variation, change in generator pole number and parallel operation etc. In analytical techniques, there are two methods mainly - loop impedance method and nodal admittance method. Two non-linear simultaneous equations in term of generated frequency ' $a$ ' and magnetizing reactance ' $\mathrm{X}_{\mathrm{m}}$ ' is obtained by equating the real and imaginary terms of the complex loop impedances respectively to zero, for any given load and speed. These equations are then solved by the NewtonRaphson method. After knowing the values of ' $a$ ' and ' $X_{m}$ ' and further with the help of the magnetization curve of machine, the equivalent circuit is completely solved and the steady-state performance of the SElG can be easily determined. Similarly in Nodal admittance method, we consider the admittances connected across the nodes which define the air gap. This method gives an algebraic expression as function of magnetizing reactance ' $X_{m}$ ' and frequency ' $a$ '. On equating the sum of real parts to zero and the sum of imaginary parts to zero, ' $X_{m}$ ' and ' $a$ ' are evaluated mathematically. In order to estimate the performance of a SEIG, The conventional equivalent circuit of an induction motor shown in Figure 1. Various parameters like Stator resistance, leakage reactance, rotor resistance, leakage reactance referred to stator, un-saturated magnetizing reactance representing core loss branch of the machine are to be found using various tests on the machine such as no load test and blocked rotor test.

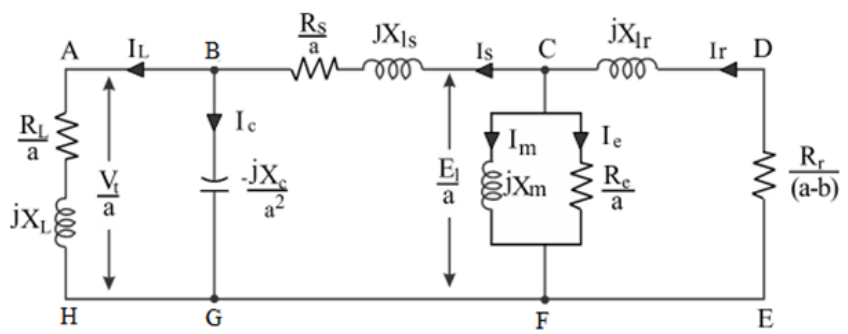

Fig 1: Per phase equivalent circuit of self-excited induction generator

$$
\begin{aligned}
& Z_{\mathrm{AH}}=\mathrm{R}_{\mathrm{L}} / \mathrm{a}+\mathrm{j} \mathrm{X}_{\mathrm{L}} \\
& \mathrm{Z}_{\mathrm{BG}}=-\mathrm{j} \mathrm{Xc} / \mathrm{a}^{2} \\
& \mathrm{Z}_{\mathrm{BC}}=\mathrm{R}_{\mathrm{s}} / \mathrm{a}+\mathrm{j} X_{\mathrm{s}} \\
& \mathrm{Z}_{\mathrm{CF}}=\mathrm{R}_{\mathrm{e}} / \mathrm{a} \| \mathrm{j} X_{\mathrm{m}} \\
& \mathrm{Z}_{\mathrm{CE}}=\left(\mathrm{R}_{\mathrm{r}} /(\mathrm{a}-\mathrm{b})+\mathrm{j} \mathrm{X}_{\mathrm{r}}\right) \\
& \mathrm{Z}=\left(\mathrm{Z}_{\mathrm{CF}} \| \mathrm{Z}_{\mathrm{CE}}\right)+\mathrm{Z}_{\mathrm{BC}}+\left(\mathrm{Z}_{\mathrm{AH}}+\mathrm{Z}_{\mathrm{BG}}\right)
\end{aligned}
$$

Solving the equivalent circuit of Figure 1, the results in a single loop equation comes to be $\mathrm{I}_{\mathrm{s}} * \mathrm{Z}=0$.

For successful voltage build up in SEIG, $I_{\mathrm{s}}$ cannot be zero hence $\mathrm{Z}$ should be zero. Thus by separating the real and imaginary components of $\mathrm{Z}$ and by putting all the values of parameters we get two non-linear simultaneous 
equations. These two equations are obtained in terms of machine parameters, speed, capacitive reactance, load resistance/reactance, magnetizing reactance $X_{m}$ and generated frequency a.

$$
\begin{aligned}
& \operatorname{Real}\left(X_{m}, a\right)=P_{1} X_{m} a^{5}+P_{2} X_{m} a^{4}+\left(P_{3} X_{m}+P_{4}\right) a^{3}+\left(P_{5} X_{m}+P_{6}\right) a^{2}+\left(P_{7} X_{m}+A_{8}\right) a+P_{9} X_{m}+P_{10} \\
& \text { Imaginary }\left(X_{m}, a\right)=\left(Q_{1} X_{m}+Q_{2}\right) a^{4}+\left(Q_{3} X_{m}+Q_{4}\right) a^{3}+\left(Q_{5} X_{m}+Q_{6}\right) a^{2}+\left(Q_{7} X_{m}+Q_{8}\right) a+Q_{9}
\end{aligned}
$$

The coefficients $\left(\mathrm{P}_{1}-\mathrm{P}_{10}\right)$ and $\left(\mathrm{Q}_{1}-\mathrm{Q}_{9}\right)$ of two characteristics equations are obtained using MATLAB and are given in Appendix -III. The values of ' $\mathrm{X}_{\mathrm{m}}$ ' and ' $\mathrm{a}$ ' are determine from polynomials represented by equation $2 \& 3$ using Newton Raphson Method in MATLAB [6].

\section{FUZZY TECHNIQUE FOR SOLVING EQUIVALENT CIRCUIT}

Attempt is made to solve the polynomial equations with Fuzzy logic technique to determine the per unit value of saturated magnetizing reactance ' $\mathrm{X}_{\mathrm{m}}$ ' and generated frequency ' $\mathrm{a}$ '. Fuzzy logic is a simple, rule based approach to solve a problem rather than attempting mathematical modeling. These values are calculated by ANN, genetic algorithm by another authors also [9-12]. The values of saturated magnetic reactance and generated frequency are compared with ANN approach by varying the machine parameters like stator resistance, stator reactance, rotor resistance and rotor reactance. The Fuzzy model is also implement to model the behavior of SEIG with lagging power factor loads under three operating conditions i.e. variable load operation, variable speed operation and variable capacitance operation.

\subsection{FUZZY MODE BLOCK DIAGRAM}

In this approach the classification of fuzzy sets into various linguistic variables for which different membership functions are to be formed.We take nine inputs and two outputs. The inputs are rotor resistance ' $R_{r}$ ', stator resistance ' $R_{s}$ ' rotor leakage reactance ' $X_{r}$ ' and stator leakage reactance ' $X_{s}$ ' power factor ' $P F$ ', speed ' $N$ ', capacitance ' $\mathrm{C}$ ' and load admittance ' $\mathrm{Y}$ ' in per unit and two outputs as magnetic reactance ' $\mathrm{X}_{\mathrm{m}}$ ' and generated frequency' $a$ '.Membership function for all parameters are set for different ranges. Six membership function are extreme low, very low, low, medium, high and very high are used in this paper so that wide range of out put can be taken and extremely close values of all the machine parameters can be used. Output variables ' $X_{m}$ ' \& ' $a$ ' also have six membership functions as extreme low, very low, low, medium, high and very high. In this approach we can vary the range the member ship function are as per our requirement .More the range of membership function more rules are made and more accuracy in result can be achieved. The Proposed Fuzzy model is given in Figure 2.

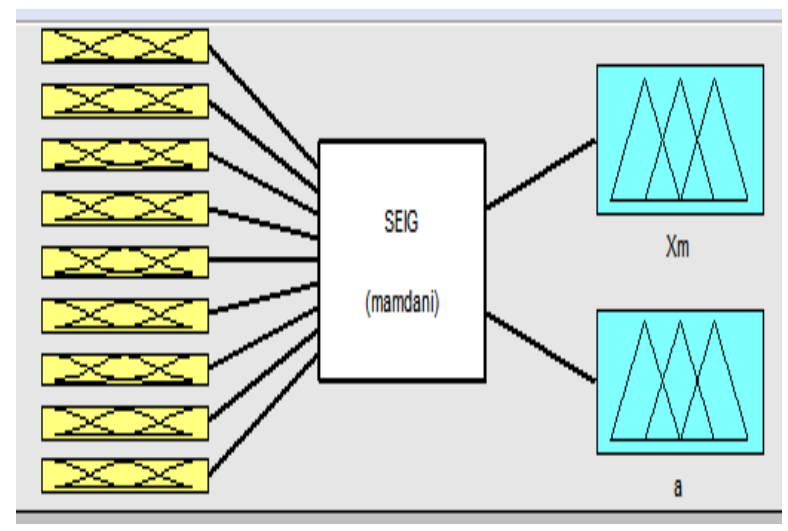

Fig. 2: Fuzzy model of SEIG to find $\mathrm{X}_{\mathrm{m}}$ and a 


\subsection{FUZZY RULES}

The proposed Fuzzy model of SEIG is made with input-output parameters obtained from analytical technique using MATLAB programming corresponding to randomly chosen input variables. The range of all input variables must be chosen very carefully and these should be compatible to real life applications of induction machine as self excited induction generator. The range of stator and rotor resistance can be varied from 4-8 percent. Triangular member ship function is used to create the rule table for fuzzy approach. The linguistic variables of the membership functions are given as extreme low $(\mathrm{EL})$, very low $(\mathrm{VL})$, low $(\mathrm{L})$, medium $(\mathrm{M})$, high $(\mathrm{H})$, very high $(\mathrm{VH})$ and extreme high $(\mathrm{EH})$ are shown below in Table 1.This table shows rules when rotor resistance is changed. The other rules for varying the parameters are also like that and results are noted for comparison.

\begin{tabular}{|c|c|c|c|c|c|c|c|c|c|c|}
\hline$R_{r}(E L)$ & $R_{s}$ & $X_{r}$ & $X_{s}(E H)$ & $R_{e}$ & $Y$ & $P F$ & $N$ & $C$ & $X_{m}(E L)$ & $a(V H)$ \\
\hline$R_{r}(V H)$ & $R_{s}$ & $X_{r}$ & $X_{s}(V H)$ & $R_{e}$ & $Y$ & $P F$ & $N$ & $C$ & $X_{m}(V L)$ & $a(V H)$ \\
\hline$R_{r}(H)$ & $R_{s}$ & $X_{r}$ & $X_{s}(V H)$ & $R_{e}$ & $Y$ & $P F$ & $N$ & $C$ & $X_{m}(L)$ & $a(H)$ \\
\hline$R_{r}(M)$ & $R_{s}$ & $X_{r}$ & $X_{s}(H)$ & $R_{e}$ & $Y$ & $P F$ & $N$ & $C$ & $X_{m}(M)$ & $a(M)$ \\
\hline$R_{r}(V H)$ & $R_{s}$ & $X_{r}$ & $X_{s}(E H)$ & $R_{e}$ & $Y$ & $P F$ & $N$ & $C$ & $X_{m}(H)$ & $a(V H)$ \\
\hline$R_{r}(E L)$ & $R_{s}$ & $X_{r}$ & $X_{s}(E L)$ & $R_{e}$ & $Y$ & $P F$ & $N$ & $C$ & $X_{m}(V H)$ & $a(V H)$ \\
\hline
\end{tabular}

Table $1:$ Fuzzy Rules for varying machine parameter

\subsection{IMPLIMENTATION OF FUZZY RULES}

In this section influence of machine parameters (stator and rotor parameters) on its performance of SEIG is predicted using fuzzy model .The proposed Fuzzy model of SEIG is implemented to determine the magnetic reactance and generated frequency requirements under varying conditions stator resistance, stator reactance, rotor resistance and rotor reactance. In the first case the induction machine operation is carried with constant load, constant capacitance and constant speed at unity power factor The speed is taken as $1554 \mathrm{rpm}$, capacitance is taken as 26.93 micro farad and load is taken as $120 \mathrm{ohm}$. The stator resistance is varied from 0.0200 to $0.952 \mathrm{pu}$ in eight steps which can be then easily understood from the tabular form. To investigate the performance of the proposed Fuzzy model, input data is presented to Figure 3, with Variable machine parameters and other conditions (Speed $=1584 \mathrm{rpm}$ and capacitance $=26.93$ microfarad and load $120 \mathrm{ohm}$ ). . Using the fuzzy rules the values of ' $X_{\mathrm{m}}$ ' and ' $\mathrm{a}$ ' are computed with varying input data of machine parameters. The results obtained from the proposed Fuzzy model for computation of $X_{m}$ and 'a' with varying stator resistance, stator reactance, rotor resistance and rotor reactance are recorded in Table 2,3,4 and 5 which give the comparison of results obtained from analytical technique, ANN and fuzzy logic of machine. The variation of magnetizing reactance, generated frequency and with varying parameters and given conditions is shown in Figure 4, Figure 5 , Figure 6 and Figure 7. 


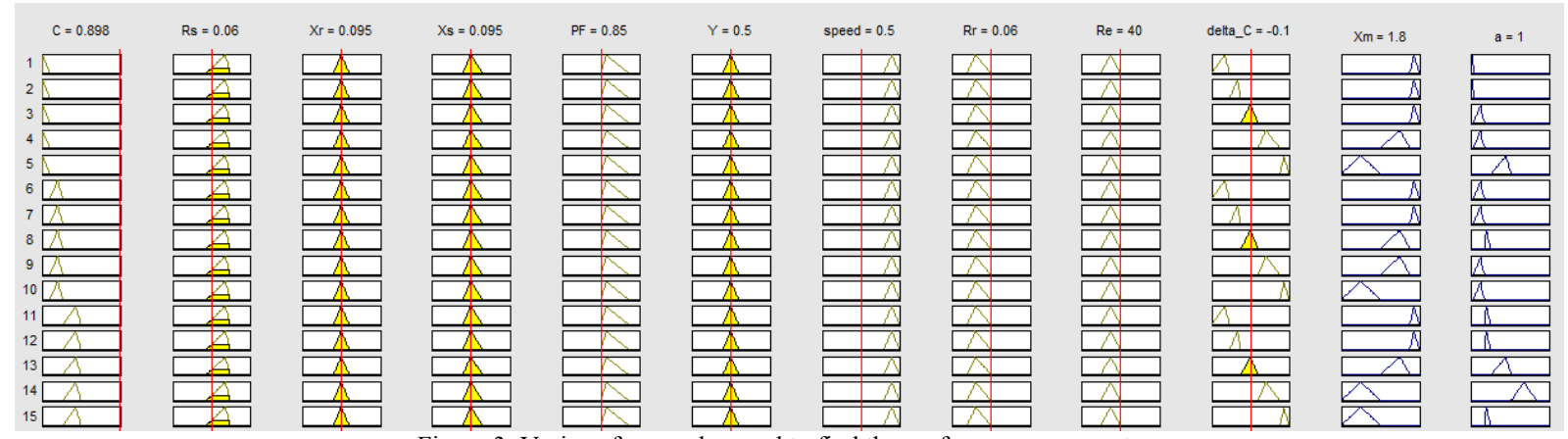

Figure 3: Various fuzzy rules used to find the performance parameters

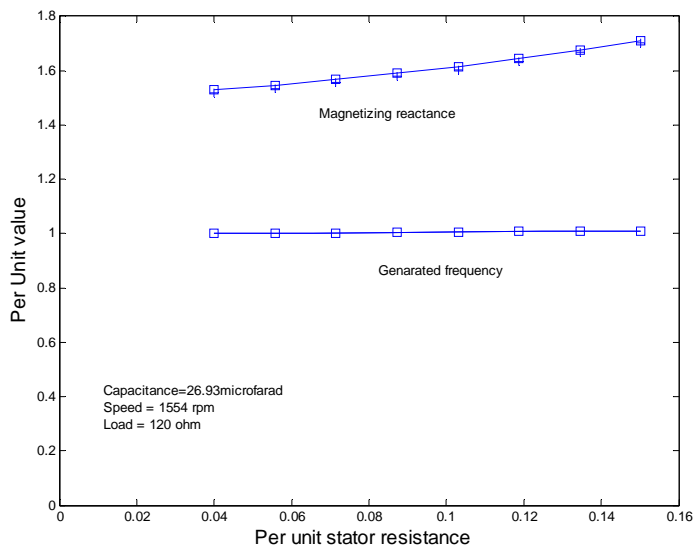

Fig. 4 Effect of Stator Resistance on Magnetizing Reactance and Generated Frequency of SEIG

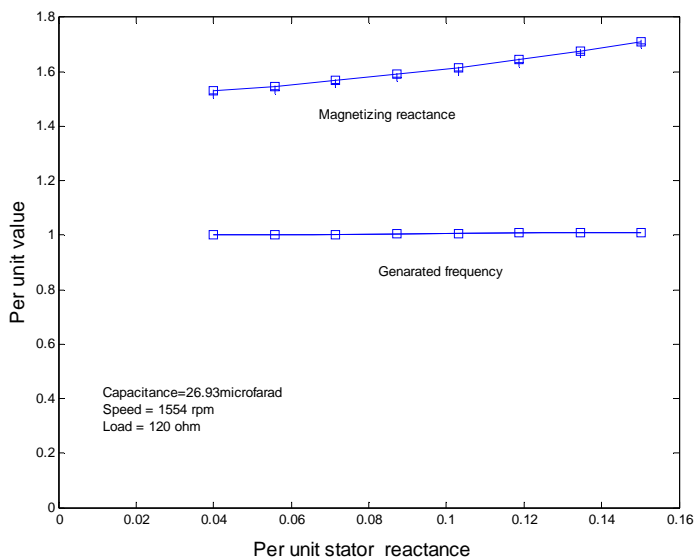

Fig. 5. Effect of Stator Reactance on Magnetizing Reactance and Generated Frequency of SEIG 


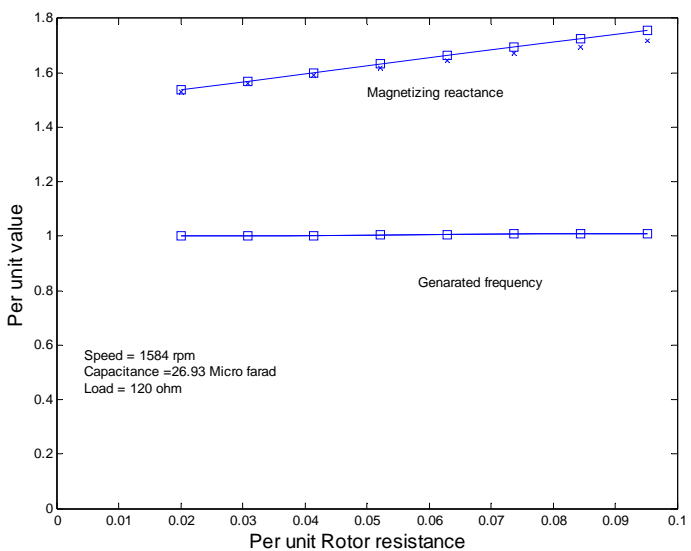

Fig. 6.: Effect of rotor Resistance on Magnetizing Resistance and Generated Frequency of SEIG

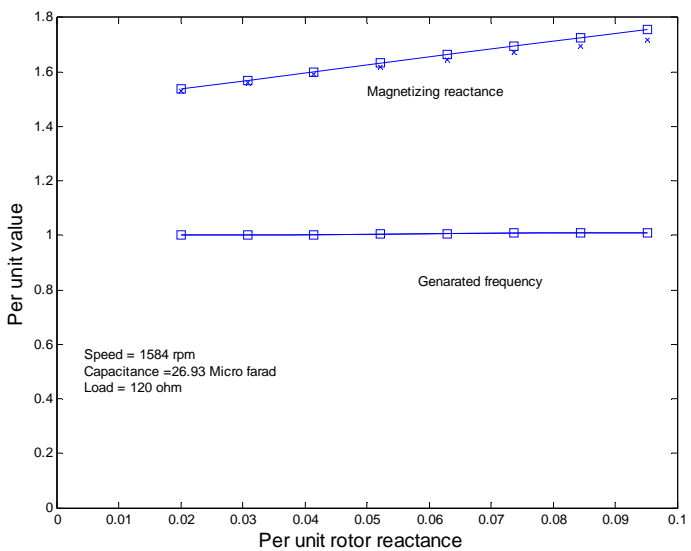

Fig.7: Effect of Rotor Reactance on Magnetizing Reactance and Generated Frequency of SEIG 


\begin{tabular}{|c|c|c|}
\hline $\begin{array}{c}\text { Stator Resistance } \\
(\mathrm{pu})\end{array}$ & $\begin{array}{c}\text { Analytical Model } \\
\text { Xm }\end{array}$ & $\begin{array}{c}\text { Fuzzy Model } \\
\text { Xm }\end{array}$ \\
\hline 0.0200 & 1.4841 & 1.4854 \\
\hline 0.0308 & 1.5162 & 1.5124 \\
\hline 0.0415 & 1.5489 & 1.5412 \\
\hline 0.0522 & 1.5822 & 1.5719 \\
\hline 0.0630 & 1.6159 & 1.6045 \\
\hline 0.0737 & 1.6502 & 1.6392 \\
\hline 0.0845 & 1.6849 & 1.6761 \\
\hline 0.0952 & 1.7203 & 1.7151 \\
\hline
\end{tabular}

Table 2 : Effect of Stator resistance on Magnetizing Reactance of SEIG

\begin{tabular}{|c|c|c|}
\hline $\begin{array}{l}\text { Rotor Resistance } \\
(\mathrm{pu})\end{array}$ & $\begin{array}{c}\text { Analytical Model } \\
\text { Xm(pu) }\end{array}$ & $\begin{array}{c}\text { Fuzzy Model } \\
\text { Xm (pu) }\end{array}$ \\
\hline 0.0200 & 1.5383 & 1.5316 \\
\hline 0.0308 & 1.5692 & 1.5609 \\
\hline 0.0415 & 1.6003 & 1.5897 \\
\hline 0.0522 & 1.6315 & 1.6176 \\
\hline 0.0630 & 1.6628 & 1.6446 \\
\hline 0.0737 & 1.6942 & 1.6705 \\
\hline 0.0845 & 1.7256 & 1.6953 \\
\hline 0.0952 & 1.7573 & 1.7190 \\
\hline
\end{tabular}


Table 3 : Effect of rotor resistance on Magnetizing Reactance of SEIG

\begin{tabular}{|c|c|c|}
\hline $\begin{array}{c}\text { Stator } \\
\text { Reactance }(\mathrm{pu})\end{array}$ & $\begin{array}{c}\text { Analytical } \\
\text { Model Xm }\end{array}$ & $\begin{array}{c}\text { Fuzzy Model } \\
\text { Xm }\end{array}$ \\
\hline 0.0400 & 1.5291 & 1.5185 \\
\hline 0.0558 & 1.5471 & 1.5356 \\
\hline 0.0715 & 1.5673 & 1.5555 \\
\hline 0.0873 & 1.5901 & 1.5785 \\
\hline 0.1030 & 1.6155 & 1.6045 \\
\hline 0.1188 & 1.6441 & 1.6340 \\
\hline 0.1345 & 1.6760 & 1.6670 \\
\hline 0.1502 & 1.7117 & 1.7038 \\
\hline
\end{tabular}

Table 4 Effect of Stator Reactance on magnetizing Reactance of SEIG

\begin{tabular}{|c|c|c|}
\hline $\begin{array}{c}\text { Rotor Reactance } \\
(\mathrm{pu})\end{array}$ & $\begin{array}{c}\text { Analytical Model } \\
\mathrm{Xm}\end{array}$ & $\begin{array}{c}\text { Fuzzy Model } \\
\text { Xm }\end{array}$ \\
\hline 0.0400 & 1.4835 & 1.4787 \\
\hline 0.0558 & 1.5149 & 1.5069 \\
\hline 0.0715 & 1.5478 & 1.5377 \\
\hline 0.0873 & 1.5825 & 1.5713 \\
\hline 0.1030 & 1.6191 & 1.6081 \\
\hline 0.1188 & 1.6578 & 1.6483 \\
\hline 0.1345 & 1.6989 & 1.6922 \\
\hline 0.1502 & 1.7426 & 1.7403 \\
\hline
\end{tabular}

Table 5: Effect of rotor Reactance on magnetizing Reactance of SEIG

\subsection{IMPLIMENTATION OF FUZZY MODEL OF SEIG ON LAGGING POWER FACTOR LOAD}

The Fuzzy rules are also implemented to model the behavior of SEIG with lagging power factor loads under three operating conditions i.e. variable load operation, variable speed operation and variable capacitance operation. The results of fuzzy model depicting the effect of varying load, speed and terminal capacitance on the magnetizing reactance and generated frequency of machine with lagging power factor loads is shown through Fig 7 - Fig 10 . 


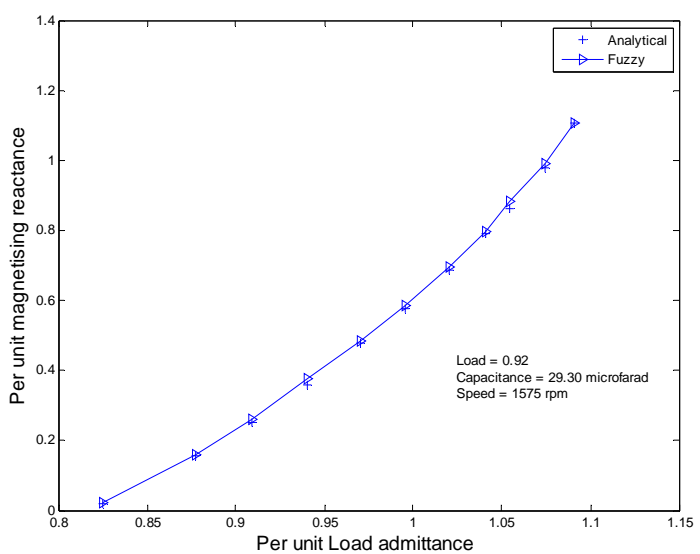

Fig. 7 : Effect of Load Admittance on Magnetizing Reactance for Lagging Power Factor Load

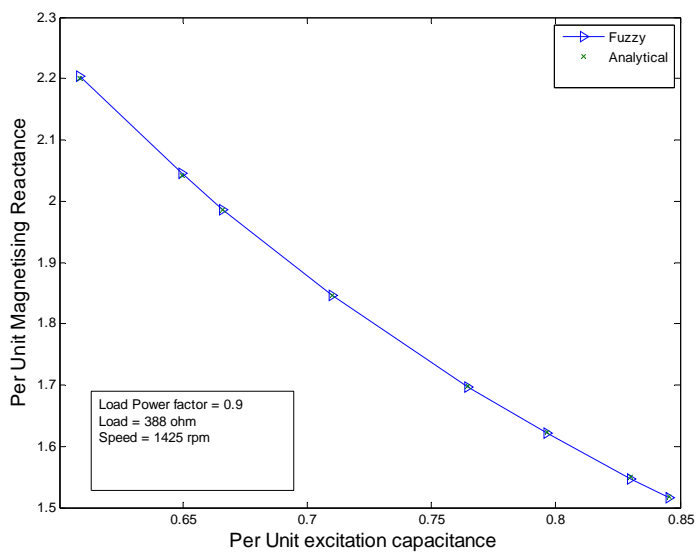

Fig. 8 :Effect of Excitation Capacitance on Magnetizing Reactance for Lagging Power Factor Load

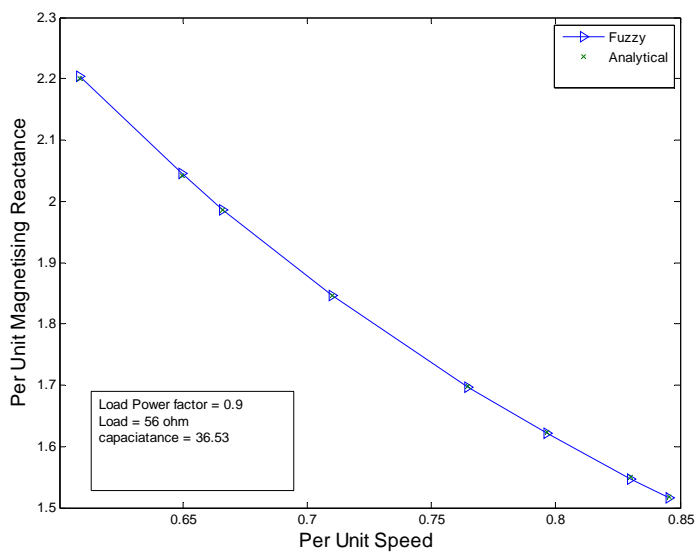

Fig.9 Effect of speed on Generated Frequency for Lagging Power Factor Load 


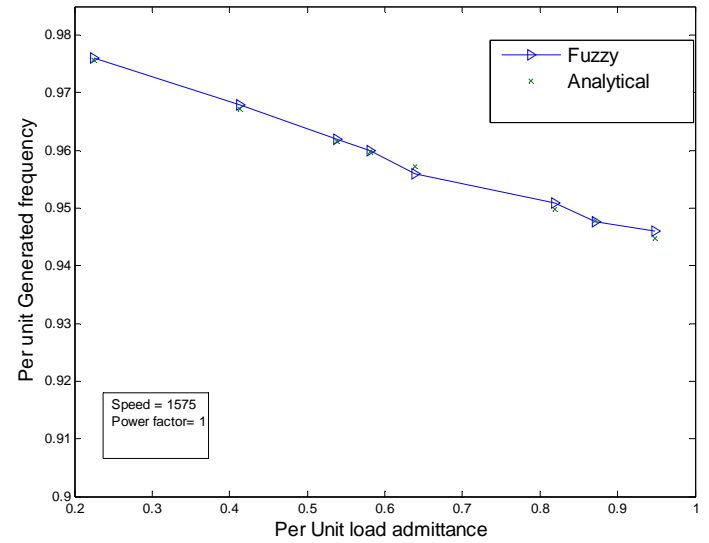

Fig.10: Effect of Load Admittance on Generated Frequency for Lagging Power Factor Load

\section{CONCLUSION}

In this application, intelligent approach, based on fuzzy logic has been implemented successfully for steady state analysis of self-excited induction generators under different machine parameters The proposed technique has shown that, it is reliable accurate and simple compared to the conventional methods Attempt is made for the pre evaluation process using fuzzy logic approach, which is simple. In this technique machine parameters are assumed to be varying from 4 to 8 percent. It is also observed that the saturated magnetizing reactance of self-excited induction generator is more in case of lagging power factor loads. The generated frequency is not affected much with lagging power factor loads. It is observed that frequency with poor factor loads is higher than unity power factor for the same value of load impedance. The results obtained from fuzzy results are compared with analytical and found to in good agreement thus validates the technique. This technique can be extended to improve the accuracy by using trapezoidal member ship function and simultaneously varying the machine parameters involved in the performance evaluation of SEIG. The technique used can be implemented to any machine

\section{ACKNOWLEDGMENT}

Authors are thankful Punjab Technical University Kapurthala and Management of Doaba Group of colleges Mohali for providing the lab for experimentation work and MATLAB tools for doing research .

\section{REFERENCES}

[1] H. C. Rai and B. Singh, "Investigations on single-phase self-excited induction generator for standby power," IEEE conference, Vol. 3, 1996.

[2] T.F. Chan, Member IEEE, “ Self-Excited Induction Generators Driven by Regulated and Unregulated Turbines "IEEE Transactions on Energy Conversion, Vol. 11, No. 2, June 1996.

[3] T. F. Chan, "Steady state analysis of self-excited induction generators ,’IEEE Trans. On Energy Conversion, Vol. 9, pp. 288-296, June 1994.

[4] T. F. Chan and L. L. Lai, “A novel excitation scheme for a stand-alone 3-phase induction generator supplying single-phase loads ,'IEEE Trans. on Energy Conversion, Vol. 19, pp. 136 - 143, Mar. 2004.

[5] Y. N. Anagreh, "A new approach for steady-state analysis of single-phase self excited induction generator," IEEE CNF, vol. 2, pp. 509 512, Sept. 2004

[6] Vineet P. Chandran and Shelly Vadhera "Comparison of nodal admittance and loop impedance methods for self excited induction generator", IJOAET E-ISSN 0976-3945.

[7] B. Singh and L.B. Shilpkar "Steady-state analysis of single-phase self-excited induction generator" IEE Proc. Generation Transmission Distribution Vol. 146, No. 5, September 1999

[8] M. H. Haque "A Novel Method of Evaluating Performance Characteristics of a Self-Excited Induction Generator", IEEE Transactions on energy conversions, Vol. 24, NO. 2, June 2009

[9] R.S Khela, R. K Bansa 1, K. S. Sandhu and Ashok Kumar Goel "Application of Artificial Neural Network for Analysis of Self-Excited Induction Generator" JCS \& T, Vol. 6 No. 2. 
[10] R. K. Bansal ,Raja Singh Khela, K. S. Sandhu, and A. K. Goel " Cascaded ANN for Evaluation of Frequency and air gap voltage of SelfExcited Induction Generator” International Journal of Electrical and Electronics Engineering, 2007.

[11] Raja Singh Khela, R. K. Bansal, K. S. Sandhu, and A. K. Goel "Cascaded ANN for Evaluation of Frequency and Air-gap Voltage of SelfExcited Induction Generator" World Academy of Science, Engineering and Technology ,2007

[12] K.S. Sandhu and S.P.Jain "Steady State Operation of Self-Excited Induction Generator with Varying Wind Speeds" International journal of circuits systems and signal processing .Issue 1, Volume 2, 2008

[13] S.P.Singh,B.Singh,M.P.Jain "Comparative study on the performance of a commercially designed induction generator with Induction motors operating as self excited induction generators" IEE Proceedings S-C, Vol. 140, No. 5, September 1993

[14] Mr.M. Senthil kumar "Optimal capacitor For maximum output power of Self Excited Induction Generator Using Fuzzy Logic approach" IJCSE Vol.02,2010.

[15] A. L. Alolah and M. A. Alkanhal, "Optimization-based steady state analysis of three phase self-excited induction generator," IEEE Trans. Energy Convers., vol. 15, no. 1, pp. 61-65,

[16] S. Rajakaruna and R. Bonert, "A technique for the steady-state analysisof a self- excited induction generator with variable speed," IEEE Trans.Energy Convers., vol. 8, no. 4, pp. 757-761, Dec. 1993.

[17] S. P. Singh, B. P. Singh, and M. P. Jain, "Comparative study on the performance of a commercially designed induction generator with inducton motors operating as self excited induction generators," in Proc Inst.Electr. Eng., vol. 140, no. 5, pp. 374- 380, 1993.

Nomenclature:

\section{Appendix 1}

$\mathrm{R}_{\mathrm{r},} \quad \mathrm{X}_{\mathrm{r}}=$ Rotor resistance and reactance

$\mathrm{R}_{\mathrm{s}}, \mathrm{X}_{\mathrm{s}}=$ Stator resistance and reactance

$\mathrm{R}_{\mathrm{L}}, \mathrm{X}_{\mathrm{L}}=$ Load resistance and reactance

$\mathrm{R}_{\mathrm{e}} \quad=$ Core loss resistance

$\mathrm{X}_{\mathrm{m}} \quad=$ Saturated magnetizing reactance

$\mathrm{X}_{\mathrm{mu}} \quad=$ Unsaturated magnetizing reactance

$\mathrm{X}_{\mathrm{C}} \quad=$ Per phase capacitive reactance

a $\quad=$ Generated frequency

$\mathrm{b} \quad=$ Ratio of actual rotor speed to synchronous speed

$\mathrm{I}_{\mathrm{S}} \quad=$ Stator current

$\mathrm{I}_{\mathrm{L}} \quad=$ Load current

$\mathrm{I}_{\mathrm{r}} \quad=$ Rotor current

Ic $\quad=$ Capacitive current

$\mathrm{E}_{1} \quad=$ Air gap voltage per phase

$\mathrm{Z}=$ Impedance of complete circuit

Polynomial Coefficients:

\section{Appendix -II}

$\mathrm{P}_{1}=-\left(\mathrm{X}_{1 \mathrm{~s}} \mathrm{X}_{\mathrm{lr}} \mathrm{X}_{\mathrm{L}}\right)$

$\mathrm{P}_{2}=\left(\mathrm{X}_{1 \mathrm{~S}} \mathrm{X}_{1 \mathrm{r}} \mathrm{X}_{\mathrm{L}}\right) \mathrm{b}$

$P_{3}=X_{1 s}\left(R_{r} R_{L}+R_{e} R_{L}+X_{1 r} X c\right)+X_{1 r}\left(R_{e} R_{1}+X_{C} X_{L}+R_{s} R_{L}\right)+X_{L}\left(R_{e} R_{r}+R_{e} R_{s}+R_{s} R_{r}\right)$

$\mathrm{P}_{4}=\mathrm{X}_{1 \mathrm{~s}} \mathrm{R}_{\mathrm{e}}\left(\mathrm{X}_{1 \mathrm{r}} \mathrm{R}_{\mathrm{L}}+\mathrm{RrX}_{\mathrm{L}}\right)+\mathrm{R}_{\mathrm{e}} \mathrm{R}_{\mathrm{s}} \mathrm{X}_{\mathrm{lr}} \mathrm{X}_{\mathrm{L}}$

$P_{5}=-X_{1 s}\left(X_{1 r} X_{c}+R_{e} R_{L}\right) b-X_{1 r}\left(R_{s} R_{L}+R_{e} R_{L}+X_{c} X_{L}\right) b-\left(R_{s} R_{e} X_{L}\right) b$

$\mathrm{P}_{6}=-\mathrm{X}_{1 \mathrm{r}} \mathrm{R}_{\mathrm{e}}\left(\mathrm{R}_{\mathrm{s}} \mathrm{X}_{\mathrm{L}}+\mathrm{X}_{1 \mathrm{~s}} \mathrm{R}_{\mathrm{L}}\right) \mathrm{b}$

$P_{7}=-X_{c} R_{r}\left(R_{s}+R_{L}\right)-X_{c} R_{e}\left(R_{s}+R_{L}+R_{r}\right)$

$\mathrm{P}_{8}=-\left(\mathrm{R}_{\mathrm{e}} \mathrm{X}_{1 \mathrm{r}} \mathrm{X}_{\mathrm{c}}\left(\mathrm{R}_{\mathrm{L}}+\mathrm{R}_{\mathrm{s}}\right)\right)-\left(\mathrm{R}_{\mathrm{e}} \mathrm{R}_{\mathrm{r}} \mathrm{X}_{\mathrm{c}}\left(\mathrm{X}_{\mathrm{L}}+\mathrm{X}_{1 \mathrm{~s}}\right)\right)-\left(\mathrm{R}_{\mathrm{e}} \mathrm{R}_{\mathrm{s}} \mathrm{R}_{\mathrm{r}} \mathrm{R}_{\mathrm{L}}\right)$;

$\mathrm{P}_{9}=\mathrm{R}_{\mathrm{e}} \mathrm{X}_{\mathrm{C}}\left(\mathrm{R}_{\mathrm{s}}+\mathrm{R}_{\mathrm{L}}\right) \mathrm{b}$

$\mathrm{P}_{10}=\mathrm{X}_{\mathrm{c}} \mathrm{X}_{1 \mathrm{r}} \mathrm{R}_{\mathrm{e}}\left(\mathrm{R}_{\mathrm{L}}+\mathrm{R}_{\mathrm{s}}\right) \mathrm{b}$

$\mathrm{Q}_{1}=\mathrm{X}_{1 \mathrm{~s}} \mathrm{X}_{\mathrm{L}}\left(\mathrm{R}_{\mathrm{e}}+\mathrm{R}_{\mathrm{r}}\right)+\mathrm{X}_{1 \mathrm{~s}} \mathrm{X}_{1 \mathrm{r}} \mathrm{R}_{\mathrm{L}}+\mathrm{X}_{1 \mathrm{r}} \mathrm{X}_{\mathrm{L}}\left(\mathrm{R}_{\mathrm{e}}+\mathrm{R}_{\mathrm{s}}\right)$

$\mathrm{Q}_{2}=\mathrm{X}_{1 \mathrm{~s}} \mathrm{X}_{1 \mathrm{r}} \mathrm{X}_{\mathrm{L}} \mathrm{R}_{\mathrm{e}}$

$\mathrm{Q}_{3}=-\mathrm{X}_{1 \mathrm{~s}}\left(\mathrm{R}_{\mathrm{e}} \mathrm{X}_{\mathrm{L}}+\mathrm{X}_{\mathrm{lr}} \mathrm{R}_{\mathrm{L}}\right) b-\mathrm{X}_{1 \mathrm{r}} \mathrm{X}_{\mathrm{L}}\left(\mathrm{R}_{\mathrm{s}}+\mathrm{R}_{\mathrm{e}}\right) b$

$\mathrm{Q}_{4}=-\left(\mathrm{X}_{1 \mathrm{~s}} \mathrm{X}_{1 \mathrm{r}} \mathrm{X}_{\mathrm{L}} \mathrm{R}_{\mathrm{e}}\right) \mathrm{b}$

$\mathrm{Q}_{5}=-\mathrm{X}_{\mathrm{c}} \mathrm{R}_{\mathrm{e}}\left(\mathrm{X}_{1 \mathrm{~s}}+\mathrm{X}_{1 \mathrm{r}}+\mathrm{X}_{\mathrm{L}}\right)-\mathrm{R}_{\mathrm{L}} \mathrm{R}_{\mathrm{e}}\left(\mathrm{R}_{\mathrm{s}}+\mathrm{Rr}\right)-\mathrm{R}_{\mathrm{L}}\left(\mathrm{X}_{1 \mathrm{r}} \mathrm{X}_{\mathrm{c}}+\mathrm{R}_{\mathrm{r}} \mathrm{R}_{\mathrm{s}}\right)-\mathrm{X}_{\mathrm{c}}\left(\mathrm{R}_{\mathrm{s}} \mathrm{X}_{1 \mathrm{r}}+\mathrm{X}_{1 \mathrm{~s}} \mathrm{R}_{\mathrm{r}}+\mathrm{X}_{\mathrm{L}} \mathrm{R}_{\mathrm{r}}\right)$

$\mathrm{Q}_{6}=-\mathrm{R}_{\mathrm{e}} \mathrm{X}_{\mathrm{Ir}}\left(\mathrm{X}_{1 \mathrm{~s}} \mathrm{X}_{\mathrm{c}}+\mathrm{X}_{\mathrm{c}} \mathrm{X}_{\mathrm{L}}+\mathrm{R}_{\mathrm{s}} \mathrm{R}_{\mathrm{L}}\right)-\mathrm{R}_{\mathrm{r}} \mathrm{R}_{\mathrm{e}}\left(\mathrm{X}_{1 \mathrm{~s}} \mathrm{R}_{\mathrm{L}}+\mathrm{R}_{\mathrm{s}} \mathrm{X}_{\mathrm{L}}\right)$

$\mathrm{Q}_{7}=\mathrm{R}_{\mathrm{e}}\left(\mathrm{X}_{1 \mathrm{r}} \mathrm{X}_{\mathrm{c}}+\mathrm{X}_{1 \mathrm{~s}} \mathrm{X}_{\mathrm{c}}+\mathrm{X}_{\mathrm{L}}+\mathrm{R}_{\mathrm{s}} \mathrm{R}_{\mathrm{I}}\right) \mathrm{b}+\mathrm{X}_{\mathrm{c}} \mathrm{X}_{\mathrm{rr}}\left(\mathrm{R}_{\mathrm{s}}+\mathrm{R}_{\mathrm{L}}\right) \mathrm{b}$

$\mathrm{Q}_{8}=\mathrm{R}_{\mathrm{e}} \mathrm{X}_{1 \mathrm{r}}\left(\mathrm{X}_{1 \mathrm{~s}} \mathrm{X}_{\mathrm{c}}+\mathrm{X}_{\mathrm{c}} \mathrm{X}_{\mathrm{L}}\right) \mathrm{b}+\left(\mathrm{X}_{1 \mathrm{r}} \mathrm{R}_{\mathrm{e}} \mathrm{R}_{\mathrm{L}} \mathrm{R}_{\mathrm{s}}\right) \mathrm{b}$

$\mathrm{Q}_{9}=\mathrm{R}_{\mathrm{e}} \mathrm{X}_{\mathrm{c}} \mathrm{R}_{\mathrm{r}}\left(\mathrm{R}_{\mathrm{L}}+\mathrm{R}_{\mathrm{s}}\right)$ 


\section{AUTHOR PROFILE}

${ }^{1}$ Er.Ashish Sharma passed B.Tech in 2001 and M.Tech in 2006 from Punjab Technical university Kapurthala. Presently he is working as Astt. Prof. in Department of Electrical DAV Instutute of engineering and Technology Jalandhar .He is pursuing his PhD from Punjab Technical University Kapurthala.

${ }^{2}$ Dr Raja Singh Khela He graduated in Electrical Engg. From Institution of Engineers, Calcutta in 1985. He Passed his Masters Degree (with Distinction) from Punjab University, Chandigarh (India) in the year 1990. He did his PhD in 2009 from Punjab Technical University, Jallandhar (India). Presently serving as Director at Doaba group of colleges ,Kharar ,Mohali ,Punjab India 